\title{
Establishing glycaemic control with continuous subcutaneous insulin infusion in children and adolescents with type 1 diabetes: experience of the PedPump Study in 17 countries
}

\author{
T. Danne • T. Battelino • P. Jarosz-Chobot • \\ O. Kordonouri • E. Pánkowska • J. Ludvigsson • \\ E. Schober • E. Kaprio • T. Saukkonen • M. Nicolino • \\ N. Tubiana-Rufi • C. Klinkert • H. Haberland • \\ A. Vazeou $\cdot$ L. Madacsy $\cdot$ D. Zangen $\cdot$ V. Cherubini $\cdot$ \\ I. Rabbone $\cdot \mathrm{S}$. Toni $\cdot \mathrm{C}$. de Beaufort . \\ W. Bakker-van Waarde • N. van den Berg • I. Volkov • \\ R. Barrio • R. Hanas $\cdot$ U. Zumsteg • B. Kuhlmann • \\ C. Aebi $\cdot$ U. Schumacher $\cdot$ S. Gschwend • \\ P. Hindmarsh • M. Torres • N. Shehadeh • M. Phillip • \\ and the PedPump Study Group
}

Received: 19 March 2008 / Accepted: 20 May 2008 / Published online: 1 July 2008

(C) Springer-Verlag 2008

\begin{abstract}
Aims/hypothesis To assess the use of paediatric continuous subcutaneous infusion (CSII) under real-life conditions by analysing data recorded for up to 90 days and relating them to outcome.
\end{abstract}

Electronic supplementary material The online version of this article (doi:10.1007/s00125-008-1072-2) contains a list of the members of the PedPump Study Group, which is available to authorised users.

\footnotetext{
T. Danne $(\bowtie)$

Kinderkrankenhaus auf der Bult, Hanover,

Janusz-Korczak-Allee 12,

30173 Hanover, Germany

e-mail: danne@hka.de

T. Battelino

University Children's Hospital,

Ljubljana, Slovenia

P. Jarosz-Chobot

Medical University of Silesia,

Katowice, Poland

O. Kordonouri

Pediatric Clinic

Charité, Berlin, Germany

E. Pánkowska

Medical University of Warsaw,

Warsaw, Poland

Methods Pump programming data from patients aged 018 years treated with CSII in 30 centres from 16 European countries and Israel were recorded during routine clinical visits. $\mathrm{HbA}_{1 \mathrm{c}}$ was measured centrally. 
Results A total of 1,041 patients (age: $11.8 \pm 4.2$ years; diabetes duration: $6.0 \pm 3.6$ years; average CSII duration: $2.0 \pm 1.3$ years; $\mathrm{HbA}_{1 \mathrm{c}}: 8.0 \pm 1.3 \%$ [means $\pm \mathrm{SD}$ ]) participated. Glycaemic control was better in preschool $(n=142 ; 7.5 \pm$ $0.9 \%$ ) and pre-adolescent (6-11 years, $n=321 ; 7.7 \pm 1.0 \%$ ) children than in adolescent patients (12-18 years, $n=578$; $8.3 \pm 1.4 \%)$. There was a significant negative correlation between $\mathrm{HbA}_{1 \mathrm{c}}$ and daily bolus number, but not between $\mathrm{HbA}_{1 \mathrm{c}}$ and total daily insulin dose. The use of $<6.7$ daily boluses was a significant predictor of an $\mathrm{HbA}_{1 \mathrm{c}}$ level $>7.5 \%$. The incidence of severe hypoglycaemia and keto-

\section{N. Tubiana-Rufi}

CHU Robert Debré, APPH,

Paris, France

\section{Klinkert}

Heart and Diabetes Center Nordrhein,

Westfalen, Bad Oeynhausen, Germany

H. Haberland

Clinic Lindenhof,

Berlin, Germany

\section{A. Vazeou \\ P\&A Kyriakou Children's Hospital, \\ Athens, Greece}

L. Madacsy

Semmelweis University,

Budapest, Hungary

\section{Zangen}

Hadassah Hebrew University Medical Center,

Jerusalem, Israel

\section{Cherubini}

Polytechnic University of Marche, Salesi Hospital,

Ancona, Italy

\section{Rabbone}

Department of Paediatrics, University of Turin, Turin, Italy

S. Toni

Meyer Paediatric Institute,

Florence, Italy

C. de Beaufort

DCCP Pediatric Clinic of Luxembourg,

Luxembourg, Luxembourg

W. Bakker-van Waarde

Beatrix Children's Hospital,

University Medical Center Groningen,

Groningen, the Netherlands

N. van den Berg

Flevo-Children's Hospital,

Almere, the Netherlands acidosis was 6.63 and 6.26 events per 100 patient-years, respectively.

Conclusions/interpretation This large paediatric survey of CSII shows that glycaemic targets can be frequently achieved, particularly in young children, and the incidence of acute complications is low. Adequate substitution of basal and prandial insulin is associated with a better $\mathrm{HbA}_{1 \mathrm{c}}$.

Keywords Adolescents $\cdot$ Children · Diabetic $\cdot \mathrm{HbA}_{1 \mathrm{c}}$. Hypoglycaemia $\cdot$ Insulin infusion systems $\cdot$ Ketoacidosis . Type 1 diabetes mellitus

I. Volkov

Russian Children's Clinical Hospital,

Moscow, Russia

R. Barrio

Hospital Ramon y Cajal,

Madrid, Spain

R. Hanas

Uddevalla Hospital,

Uddevalla, Sweden

U. Zumsteg

University Children's Hospital,

Basel, Switzerland

B. Kuhlmann

Private practice,

Basel, Switzerland

C. Aebi

Children's Hospital Wildermeth am Spitalzentrum Biel,

Biel, Switzerland

U. Schumacher

Kantonspital Münsterlingen,

Münsterlingen, Switzerland

S. Gschwend

Kantonsspital Zug,

Zug, Switzerland

P. Hindmarsh

London Centre for Paediatric Endocrinology and Diabetes,

London, UK

M. Torres

Hospital San Juan de Dios,

Barcelona, Spain

N. Shehadeh

Mayer Children Hospital,

Haifa, Israel

M. Phillip

Schneider Children's Medical Center of Israel,

Petah Tikva, Israel 


\section{Abbreviations \\ CSII continuous subcutaneous insulin infusion \\ DKA diabetic ketoacidosis \\ PPSG Pediatric Pump Study group}

\section{Introduction}

The Diabetes Control and Complications Trial showed that intensive glycaemic control in adolescents with type 1 diabetes mellitus is associated with a decreased risk of microvascular complications [1], and there is increasing evidence that control of diabetes during the prepubertal and pubertal years can also have a marked impact on the risk of such complications $[2,3]$. As a result, current guidelines recommend that the aim of treatment in children and adolescents with type 1 diabetes should be to achieve nearnormal glycaemic control as early as possible in the course of the disease $[4,5]$. This, however, is often difficult to achieve in clinical practice because of variable eating patterns and activity and unpredictable absorption of insulin in young children [5-7], and difficulties in complying with the demands of regular blood glucose monitoring and multiple daily injections in adolescents [8]. The problems involved in achieving glycaemic control in children are highlighted by data from the Hvidore study [9], which showed that the levels of glycaemic control achieved varied markedly between centres; furthermore, even when treatment was intensified following feedback from betweencentre comparisons of $\mathrm{HbA}_{1 \mathrm{c}}$ concentrations, glycaemic control was achieved in only a few centres.

Continuous subcutaneous insulin infusion (CSII) allows administration of rapid-acting insulin analogues at a variable low basal rate over $24 \mathrm{~h}$, with patient-activated boluses at mealtimes [10]; hence, this approach offers the potential for a more physiological pattern of insulin administration, and thereby better glycaemic control, than multiple daily injections. A recent consensus conference has concluded that, provided appropriate support is available, CSII is suitable for children and adolescents of all ages and may result in improved glycaemic control and quality of life with no greater risk (and possibly less risk) than multiple daily injections [11]. The use of this approach in children and adolescents is increasing [12, 13], but remains suboptimal $[14,15]$.

Modern CSII pumps store data on insulin dosage in their memory, thus allowing insulin treatment to be assessed for up to 90 days under 'real-life' conditions. This approach was used in a previous study from the Pediatric Pump Study Group (PPSG), which collected data retrospectively from 377 children from nine European countries and Israel [16]. This study found high variability, both in agedependent differences in the distribution of basal insulin and in age-independent day-to-day variations in prandial insulin dosing, which was consistent with the variations in glycaemic control that were observed in the Hvidore study [9]. However, measurement of $\mathrm{HbA}_{1 \mathrm{c}}$ was not standardised, and hence it was not possible to draw any conclusions about the level of glycaemic control achieved with CSII in these patients. Therefore, the present study was undertaken to document current practices of CSII use in a larger population of children and adolescents with type 1 diabetes in whom $\mathrm{HbA}_{1 \mathrm{c}}$ was measured centrally.

\section{Methods}

This open, cross-sectional, retrospective study collected data from children and adolescents from 30 centres in 16 European countries and Israel. To be eligible to participate in the study, each centre was required to be experienced in the use of CSII by including at least ten patients. The study was approved by the local Ethics Committee at each participating centre, and written informed consent was obtained from each patient or their parents or guardians before inclusion in the study.

Data collection Patients were included in the study if they had type 1 diabetes mellitus and were using pumps with 90 days' storage capacity that were compatible with the uploading software Medtronic MiniMed IM Pumps and Meters Version 5.0 (Medtronic International Trading Sàrl, Tolochenaz, Switzerland). Clinical data and $\mathrm{HbA}_{1 \mathrm{c}}$ values were entered in the electronic data capture system enCapture (Medtronic) at a routine clinic visit during 2004-2005. Clinical data included age, sex, duration of diabetes, date of starting pump therapy, insulin concentration, number of severe hypoglycaemic events and number of hospitalisations within the preceding 3 months. $\mathrm{HbA}_{1 \mathrm{c}}$ was measured by HPLC at the LKF Laboratorium fuer Klinische Forschung, Kiel, Germany, using the Bio-Rad Variant (Bio-Rad, Munich, Germany); these data were recorded during clinic visits. All personal data were removed on transfer of the files from the centre to the central database, in order to render the patient unidentifiable.

Insulin delivery over a 90 day period was recorded in the pump memory and data were downloaded at routine clinic visits by means of the Medtronic MiniMed Solutions Pumps and Meters software, and the patient pump profile data were linked to the corresponding clinical data file in the enCapture software. No more than one download was made for each patient.

The number of boluses and the total daily bolus amount were determined from the pump downloads. The basal insulin amount was calculated as the difference between the total daily amount and the daily bolus amount. The daily 
number of boluses, bolus amount, basal amount and total daily amount were averaged for each patient.

The safety of CSII therapy was assessed by monitoring the incidence of severe hypoglycaemia and diabetic ketoacidosis (DKA). The definition of severe hypoglycaemia was the same as that used in the Hvidore Study (hypoglycaemia causing unconsciousness or convulsions) [17]. DKA was defined as biochemical signs of ketoacidosis necessitating hospital admission (high glycosuria and ketonuria; blood glucose $>11 \mathrm{mmol} / \mathrm{l} ; \mathrm{pH}<7.3$; bicarbonate $<15 \mathrm{mmol} / \mathrm{l}$ ).

Statistical analysis For age-related analyses, patients were allocated to preschool ( $\leq 6$ years), pre-adolescent (girls: $>6$ years and $\leq 11$ years; boys: $>6$ years and $\leq 12$ years) and adolescent (girls: $>11$ years and $\leq 18$ years; boys: $>12$ years and $\leq 8$ years) groups. For continuous variables, descriptive statistics were calculated for the overall patient population and for each age group. Frequencies were calculated for categorical variables.

Correlation coefficients were calculated for selected comparisons of variables; the statistical test used was the Pearson movement correlation. For $\mathrm{HbA}_{1 \mathrm{c}}$, a two-sided Student's $t$ test was used to compare the mean value in patients in the upper 50 percentiles of bolus concentrations with that in patients in the lower 50 percentiles.

A second, exploratory, analysis was performed in a subgroup of patients $(n=142)$ who participated in the previous study [16] in order to compare the results obtained during this study with those obtained previously.

\section{Results}

A total of 1,098 patients were entered in the database. The number of patients recruited in each centre ranged from ten to 175 (median 93); for the 22 centres for which the relevant data were available, the proportion of patients receiving CSII who were recruited into the study ranged from 1.3 to $39.7 \%$ (median $20.5 \%$ ). Six centres included no preschool children, and one included no prepubertal children. Of the 1,098 patients, three were $>18$ years of age at baseline and nine had missing or incomplete baseline data. Hence, the final study population comprised 1,086 patients (507 males, 579 females). Of these, 1,082 had matching clinical, $\mathrm{HbA}_{1 \mathrm{c}}$ and pump data, and 1,041 had complete records of weight and pump data. The mean $( \pm \mathrm{SD})$ age of the 1,086 patients included in the analysis was $11.9 \pm 4.2$ years, and their mean duration of diabetes was $5.9 \pm 3.6$ years. Baseline demographic data by age group are summarised in Table 1. The indications for pump therapy were recurrent hypoglycaemia $(n=338)$, a desire for flexibility of lifestyle $(n=292)$, high $\mathrm{HbA}_{1 \mathrm{c}}(n=265)$, dawn phenomena $(n=131)$ and needle phobia $(n=54)$.
CSII data and metabolic control Overall, the mean daily insulin dose was $0.79 \pm 0.47 \mathrm{U} / \mathrm{kg}$, and the majority of patients $(91 \%)$ used a U100 concentration; $54 \%$ used NovoRapid (insulin aspart; Novo Nordisk) and $45 \%$ used Humalog (insulin lispro; Eli Lilly). The mean $( \pm \mathrm{SD})$

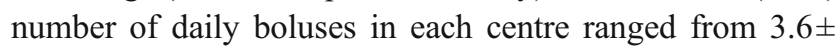
1.4 to $9.9 \pm 4.4$ (median 6.5), and the mean proportion of the total daily dose given in bolus form ranged from 41.5 to $66.9 \%$. Insulin dosages in the three age groups are summarised in Table 2. On average, preschool children used more daily boluses than the other age groups $(p<0.001)$.

The mean $\mathrm{HbA}_{1 \mathrm{c}}$ level in the overall study population was $8.0 \pm 1.3 \%$, ranging from 6.93 to 9.3 between the centres. Preschool children showed a significantly lower $\mathrm{HbA}_{1 \mathrm{c}}$ than adolescents, with a mean value of $7.6 \pm 1.0 \%$, compared with $7.7 \pm 1.1 \%$ in the pre-adolescent group and $8.3 \pm 1.4 \%(p<0.0001)$ in the adolescent group. There was a significant negative correlation between $\mathrm{HbA}_{1 \mathrm{c}}$ and the number of daily boluses $(r=-0.367 ; p<0.001)$, and between $\mathrm{HbA}_{1 \mathrm{c}}$ and the contribution of boluses to the total daily amount $(r=-0.3127 ; p<0.001$; Fig. 1a,b). In contrast, there was no correlation between $\mathrm{HbA}_{1 \mathrm{c}}$ and the total daily dose of insulin (Fig. 1c; $p=0.09$ ). In children in whom basal insulin constituted $<50 \%$ of their total daily insulin, $\mathrm{HbA}_{1 \mathrm{c}}$ was significantly better than in those with a higher proportion of basal insulin $(7.8 \pm 1.1$ vs $8.5 \pm 1.4 \%$; $p<0.01$ ).

The median number of daily boluses was 6.7. Patients using $>6.7$ daily boluses had a significantly lower $\mathrm{HbA}_{1 \mathrm{c}}$ than those using fewer boluses (median $7.6 \%$ vs $8.2 \%$, respectively. The OR for an $\mathrm{HbA}_{1 \mathrm{c}}>7.5 \%$ associated with $<6.7$ daily boluses was 2.53 (95\% CI 1.94-3.31). Other risk factors for an $\mathrm{HbA}_{1 \mathrm{c}}>7.5 \%$ were a duration of diabetes $>4.7$ years (OR 2.16, 95\% CI 1.66-2.83) and use of CSII for $>1.5$ years (OR 1.61, 95\% CI 1.24-2.10). There were no significant relationships between the risk of high $\mathrm{HbA}_{1 \mathrm{c}}$ and sex, age or daily insulin dose. $\mathrm{HbA}_{1 \mathrm{c}}$ was significantly $(p<0.001)$ higher in patients in whom high $\mathrm{HbA}_{1 \mathrm{c}}$ was the reason for using CSII than in those in whom CSII was indicated for other reasons (Fig. 2). Demographic data for patients using different numbers of daily boluses are shown in Table 3.

Safety CSII therapy was well tolerated with respect to diabetes-related adverse events. Overall, 18 patients each had a single episode of severe hypoglycaemia, giving an event rate of 6.63 per 100 patient-years. A single episode of DKA occurred in 17 patients, giving an overall event rate of 6.26 per 100 patient-years. The incidence of severe hypoglycaemia was 10.81 events per 100 patient-years in preschool children, 8.59 events per 100 patient-years in preadolescent children, and 5.22 events per 100 patient-years in the adolescent group. The 18 patients with a severe 
Table 1 Baseline demographic data by age group

\begin{tabular}{llll}
\hline Parameter & Preschool & Pre-adolescent & Adolescent \\
\hline$n$ & 148 & 326 & 612 \\
Sex (male/female) & $81 / 67(54 \% / 46 \%)$ & $170 / 156(52 \% / 48 \%)$ & $256 / 356(41 \% / 59 \%)$ \\
Body weight $(\mathrm{kg})$ & $18.3 \pm 4.37$ & $34.5 \pm 8.4$ & $58.9 \pm 12.3$ \\
Height $(\mathrm{cm})$ & $104.8 \pm 11.9$ & $139.1 \pm 11.1$ & $164.8 \pm 10.5$ \\
BMI $\left(\mathrm{kg} / \mathrm{m}^{2}\right)$ & $16.6 \pm 2.0$ & $17.6 \pm 2.2$ & $21.5 \pm 3.1$ \\
Duration of diabetes (years) & $2.5 \pm 1.3(0.3-5.9)^{\mathrm{a}}$ & $4.9 \pm 2.6(0.2-11.6)^{\mathrm{a}}$ & $7.3 \pm 3.7(0.2-18.0)^{\mathrm{a}}$ \\
Duration of CSII therapy (years) & $1.7 \pm \pm 1.1(0.04-5.0)^{\mathrm{a}}$ & $1.9 \pm 1.4(0.04-9.5)^{\mathrm{a}}$ & $2.1 \pm 1.4(0.1-14.5)^{\mathrm{a}}$ \\
\hline
\end{tabular}

Data are presented as means $\pm \mathrm{SD}$, unless stated otherwise

${ }^{\text {a }}$ Range

hypoglycaemic episode had a significantly higher insulin dosage than those without such episodes $(1.12 \pm 1.45$ vs $0.78 \pm 0.44 \mathrm{U} \mathrm{kg}^{-1}$ day $\left.^{-1} ; p<0.0025\right)$, but there was no difference in age, diabetes duration, CSII duration or number of daily boluses between the two groups. In particular, there was no association between the occurrence of severe hypoglycaemia and the $\mathrm{HbA}_{1 \mathrm{c}}$ level achieved.

The incidences of DKA in the preschool, pre-adolescent and adolescent groups were 2.70, 9.88 and 5.23 events per 100 patient-years, respectively. The 17 patients with DKA had a significantly higher $\mathrm{HbA}_{1 \mathrm{c}}(8.9 \pm 1.3$ vs $8.0 \pm 1.3 \%$; $p<0.005$ ) than those without, but did not differ significantly in other clinical variables.

A total of 43 other adverse events were reported. Of these, $63 \%$ were related to diabetes management (e.g. pump education, routine annual hospital visits, continuous glucose monitoring evaluation); $12 \%$ were related to minor surgery; and $12 \%$ were related to infections or fractures. The remaining six events were non-CSII related (e.g. eating disorder, high blood pressure, multiple sclerosis).

\section{Discussion}

CSII represents an attractive treatment option for children and adolescents with type 1 diabetes because it offers the potential for achieving all current treatment goals for these patients: near-normal glycaemic control, a low incidence of hypoglycaemia and improvement in quality of life [18]. Nevertheless, CSII remains largely underused: for example, recent data indicate that only $10-14 \%$ of paediatric diabetic patients in Germany are receiving CSII $[19,20]$. The key barrier to CSII therapy is economic, as there is no consistency regarding reimbursement from Health Authorities across Europe. In countries where funding is not readily available, access depends primarily upon the determination of the physician.

The results of this study support and extend those of the previous PPSG survey [16], and show that effective glycaemic control, with a low risk of hypoglycaemia, can be achieved with CSII therapy in many children and adolescents with type 1 diabetes. Although this survey is limited to some extent by its cross-sectional nature and a lack of a stand-

Table 2 Insulin dosage over 90 days

\begin{tabular}{llll}
\hline Parameter & Preschool & Pre-adolescent & Adolescent \\
\hline $\begin{array}{l}\text { Type of insulin } \\
\text { Lispro }\end{array}$ & $52(36)$ & $127(39)$ & $310(51)$ \\
Aspart & $87(61)$ & $197(60)$ & $296(49)$ \\
Human regular insulin & $4(3)$ & $1(0.3)$ & $2(0.3)$ \\
Insulin concentration (U) & & & $605(99)$ \\
100 & $98(68)$ & $277(85)$ & $4(1)$ \\
50 & $18(13)$ & $34(10)$ & $1(0.2)$ \\
40 & $16(11)$ & $11(3)$ & 0 \\
10 & $7(5)$ & 0 & 0 \\
Other & $5(3)$ & $4(1)$ & $0.80 \pm 0.22 ; 0.80(0-2.22)$ \\
Total daily insulin dose $(\mathrm{U} / \mathrm{kg})^{\mathrm{a}}$ & $0.93 \pm 1.13 ; 0.64(0.01-8.9)$ & $0.69 \pm 0.25 ; 0.69(0.11-3.11)$ & $6.7 \pm 2.9 ; 6.25(1.5-19.6)$ \\
No. of daily boluses & & $8.2 \pm 2.9 ; 7.7(3.1-21.4)$ & $54.2 \pm 12.3 ; 55.3(8.27-97.7)$ \\
Daily bolus/total $(\%)^{\mathrm{a}}$ & $8.8 \pm 3.6 ; 8.0(2.3-19.6)$ & $58.5 \pm 12.1 ; 59.9(22.6-98.4)$ & \\
\hline
\end{tabular}

Data are presented as $n(\%)$, unless stated otherwise

${ }^{\mathrm{a}}$ Means $\pm \mathrm{SD}$; median (range) 
a

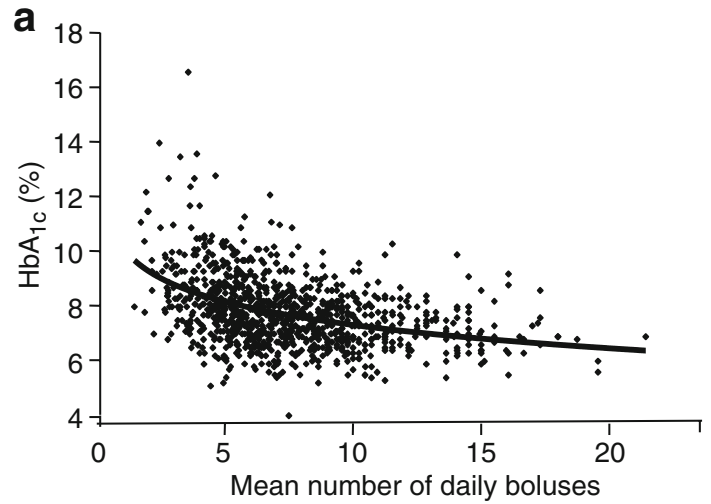

b

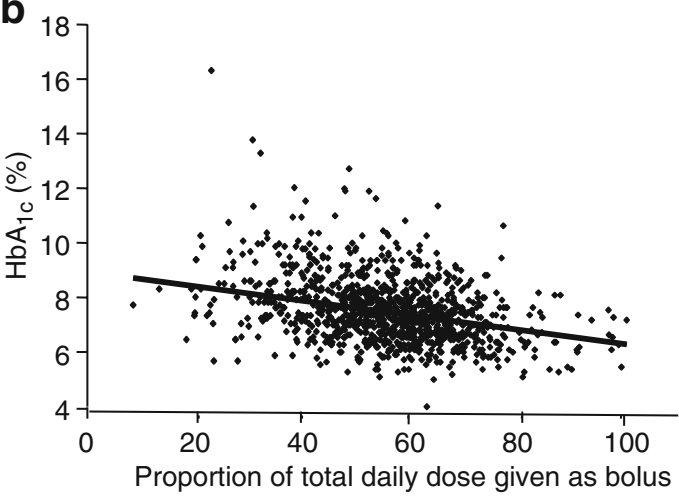

C

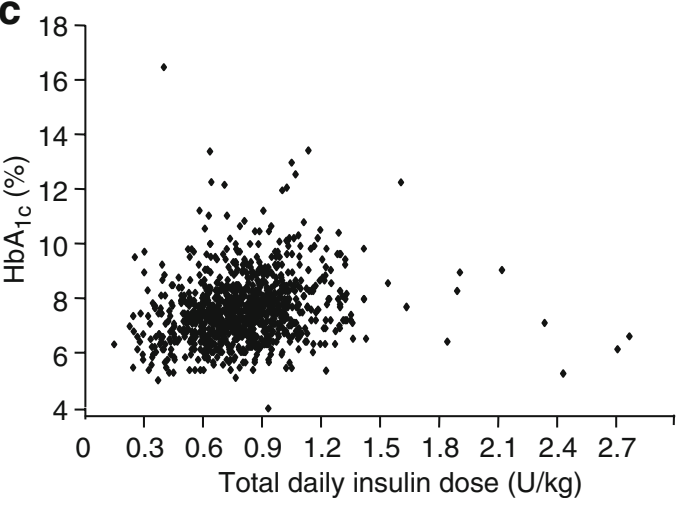

Fig. 1 Correlation between $\mathrm{HbA}_{1 \mathrm{c}}$ and: number of daily boluses with non-linear regression analysis $(r=-0.367 ; p<0.001)(\mathbf{a})$; contribution of boluses to total daily insulin dose $(r=-0.3127 ; p<0.001)$ (b); and total daily insulin amount $(p=0.09)(\mathbf{c})$

ardised approach to pump therapy in children, it nevertheless gives some insights into successful paediatric pump therapy regimens in a large patient population from 17 countries.

This study has highlighted the marked variations in patterns of pump use between centres, for example in terms of the number of daily boluses and the proportion of the daily dose given in pump form. This is consistent with the finding in the Hvidore Study that the $\mathrm{HbA}_{1 \mathrm{c}}$ concentrations achieved with intensive therapy varied markedly between centres [9]. It is important to remember that CSII and multiple daily injections are both viable strategies in children and adolescents, and that the final choice of treatment for an individual patient will require a dialogue between the patient, their parents or guardians, and the physician. Currently, strategies for tailoring CSII regimens to the needs of the individual patient tend to be empirically based, rather than evidence based [20]. Aspects that require particular attention in children and adolescents include patterns of basal and prandial insulin requirements and the selection of catheters and needles [20].

An important finding was that the use of frequent daily boluses and a lower proportion of basal insulin achieved significantly better glycaemic control than the use of fewer boluses and a higher proportion of basal insulin. This is consistent with the findings of a previous study with CSII, which showed a significant correlation between missed mealtime boluses and elevated $\mathrm{HbA}_{1 \mathrm{c}}$ [21]. Indeed, in the present study the use of more than seven boluses per day was the strongest single predictor of an $\mathrm{HbA}_{1 \mathrm{c}}$ level $<7.5 \%$; similar findings have been reported by Burdick et al. [22] The ability to deliver multiple daily doses represents an important potential advantage of CSII over multiple daily injections. This is particularly true when short-acting insulin analogues are used to achieve prandial control as was the case in $99 \%$ of the patients in the present survey. A recent editorial [23] has emphasised that basal and overnight glucose levels are the major determinants of $\mathrm{HbA}_{1 \mathrm{c}}$ levels in patients with poor glucose control, and hence such analogues produce the greatest benefit when glucose is well controlled; indeed, these analogues produce the greatest reductions in $\mathrm{HbA}_{1 \mathrm{c}}$ concentrations in patients receiving CSII therapy. It should be noted, however, that because of the lack of electronic data regarding blood glucose measurements or meals in this study it remains to be determined whether multiple boluses are predominantly associated with meals or correction for blood glucose values.

An apparently paradoxical finding of this study was that the use of CSII for $>1.5$ years was associated with a higher $\mathrm{HbA}_{1 \mathrm{c}}$ level. This probably reflects an age-related effect; as

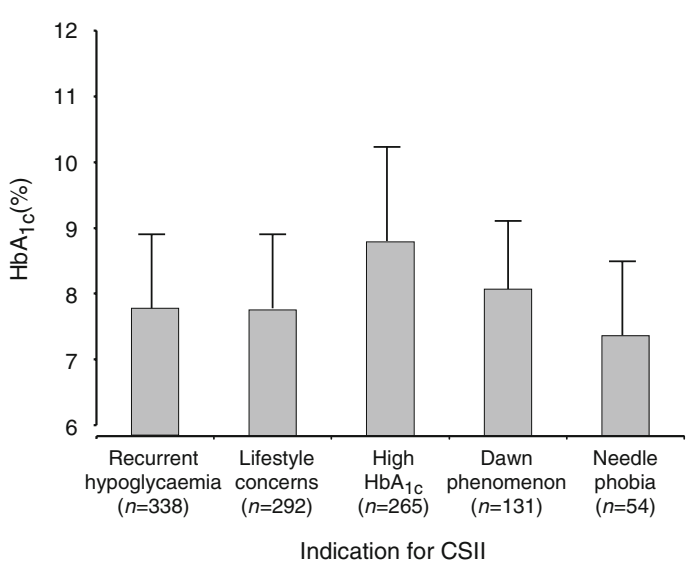

Fig. 2 Mean \pm SD $\mathrm{HbA}_{1 \mathrm{c}}$ in relation to indication for CSII therapy 
Table 3 Demographic data of patients in relation to average daily bolus number

\begin{tabular}{|c|c|c|c|c|c|}
\hline \multirow[t]{2}{*}{ Parameter } & \multicolumn{5}{|l|}{ Boluses per day } \\
\hline & $<2$ & $2-4$ & $4-7$ & $7-12$ & $>12$ \\
\hline$n$ & 6 & 102 & 429 & 424 & 87 \\
\hline Age (years) ${ }^{\mathrm{a}}$ & $17(14-19)$ & $16(3-19)$ & $13(1-19)$ & $12(0-19)$ & $11(2-19)$ \\
\hline No. of severe hypoglycaemic episodes & 0 & 2 & 9 & 5 & 1 \\
\hline No. of DKA episodes & 1 & 2 & 7 & 6 & 0 \\
\hline Diabetes duration (years) ${ }^{\mathrm{a}}$ & $11.2(6.4-17.2)$ & $6.3(0.3-19.0)$ & $5.7(0.2-17.3)$ & $4.9(0.26-15.7)$ & $3.6(0.6-18.1)$ \\
\hline CSII duration (years) ${ }^{\mathrm{a}}$ & $4.1(1.7-4.7)$ & $2.2(0.3-14.5)$ & $1.6(0.04-9.5)$ & $1.7(0.1-7.5)$ & $1.5(0.5-5.4)$ \\
\hline Total daily insulin dose (U/kg) & $0.75 \pm 0.14$ & $0.74 \pm 0.22$ & $0.81 \pm 0.56$ & $0.77 \pm 0.38$ & $0.80 \pm 0.64$ \\
\hline No. of daily boluses & $1.8 \pm 0.2$ & $3.3 \pm 0.5$ & $5.5 \pm 0.8$ & $8.9 \pm 1.3$ & $14.6 \pm 1.9$ \\
\hline $\mathrm{HbA}_{1 \mathrm{c}}(\%)$ & $10.4 \pm 1.8$ & $9.3 \pm 1.9$ & $8.2 \pm 1.2$ & $7.7 \pm 1.0$ & $7.3 \pm 0.9$ \\
\hline
\end{tabular}

Data are presented as means $\pm \mathrm{SD}$, unless stated otherwise

${ }^{a}$ median (range)

would be expected, the duration of use tended to increase with age and hence the longest durations were seen in the adolescent group, who also had the highest $\mathrm{HbA}_{1 \mathrm{c}}$ levels. Several studies have shown that $\mathrm{HbA}_{1 \mathrm{c}}$ levels in adolescents are typically $>8 \%$, and that reduction is often difficult to achieve in this group $[5,24]$. Indeed there was a negative association between age and number of boluses, and it is likely that missed mealtime boluses in the adolescent age group contributed to this [22]. In this age group, it could be beneficial to support CSII with a higher basal dose to compensate for missed boluses or additional food intake. This remains an area for further investigation. In a recent matched-pairs comparison of CSII with multiple daily injections the best long-term results were seen in the youngest age group [25]. These findings would be consistent with the finding in the present study that $\mathrm{HbA}_{1 \mathrm{c}}$ was significantly higher in patients in whom high $\mathrm{HbA}_{1 \mathrm{c}}$ was the indication for CSII therapy than in those with other indications. The finding that $\mathrm{HbA}_{1 \mathrm{c}}$ concentrations were greater in adolescents than in younger age groups could reflect greater parental supervision of treatment in young children, as reported in other studies [26].

The finding that a longer duration of CSII use was associated with higher $\mathrm{HbA}_{1 \mathrm{c}}$ is at variance with a previous meta-analysis [27], which found that patients who received pump therapy for at least 1 year showed significant improvements in glycated haemoglobin, whereas no significant improvement was seen in patients treated for $<1$ year. Nevertheless the finding that many patients included in the previous survey increased their number of boluses between the previous survey and the present study indicates that constant re-education and motivation can achieve better long-term glycaemic control with CSII. Thus, the message of our findings may be that it is important to download the electronic pump memory, and to convince the patients to take at least the minimum number of doses.
In view of the finding in this study that $\mathrm{HbA}_{1 \mathrm{c}}$ concentrations were higher in adolescents than in younger children, it seems paradoxical that there was no association between the risk of high $\mathrm{HbA}_{1 \mathrm{c}}$ and age. In contrast, in the Hvidore study, $\mathrm{HbA}_{1 \mathrm{c}}$ increased by a mean of $0.046 \%$ $(p<0.0001)$ with each year of age [9]. It is possible that in the present study any effect of age was masked by the influence of treatment duration.

The low incidence of severe hypoglycaemia in this study compares favourably with that in the Hvidore Study, in which the overall incidence of severe hypoglycaemia was 22 events per 100 patient-years and the incidence increased to almost 60 events per 100 patient-years in preschool children [17]. A previous study, involving 95 children and adolescents who were followed for a median of 28 months after starting CSII therapy, reported incidences of 7.9 events per 100 patient-years for severe hypoglycaemia and 0.7 events per 100 patient-years for DKA [28]. The even higher rate of DKA in the present study may be a reason for concern as errors in pump use could have been a potential cause. However, the significantly higher $\mathrm{HbA}_{1 \mathrm{c}}$ in the DKA group, and the lack of an association with age or CSII duration, make it likely that similar risk factors for DKA apply with CSII as with injection therapy [29].

As noted above, a possible limitation of this study is the open and uncontrolled design. However, the study was designed to investigate the efficacy and safety of CSII therapy in a large patient population under 'real-life' conditions. Such studies can provide important insights into the benefits and risks of a treatment in routine clinical practice, in contrast to the controlled conditions that prevail in clinical trials [30]. The ability to download data recorded in real time under everyday conditions in a large group of children from many different countries and cultures should provide important insights into the optimal use of CSII therapy, which arguably might not be apparent in rando- 
mised controlled trials. These insights should facilitate the identification of patients who would derive most benefit from CSII therapy. A particular strength of this study was the centralised measurement of $\mathrm{HbA}_{1 \mathrm{c}}$, which eliminated the possibility of inter-centre variability in $\mathrm{HbA}_{1 \mathrm{c}}$ measurements, thus facilitating analysis of factors affecting glycaemic control during CSII.

In conclusion, this study has shown that CSII provides convenient and flexible insulin delivery during routine treatment in many children and adolescents with type 1 diabetes. It has also highlighted the importance of frequent daily boluses and $<50 \%$ basal insulin for good glycaemic control, which is relevant to both CSII and multiple dose insulin therapy. A follow-up longitudinal study will investigate the long-term outcome in these patients.

Acknowledgements The contribution of the members of the PedPump Study Group and others who assisted the study is gratefully acknowledged. Please see the Electronic supplementary material for a full list of names of those involved.

Duality of interest Financial support for this study was provided by Medtronic International Trading Sàrl.

\section{References}

1. DCCT/EDIC Research Group (2001) Beneficial effects of intensive therapy of diabetes during adolescence: outcomes after the conclusion of the Diabetes Control and Complications Trial. J Pediatr 139:804-812

2. Danne T, Kordonouri O, Hovener G, Weber B (1997) Diabetic angiopathy in children. Diabet Med 14:1012-1025

3. Amin R, Bahu TK, Widmer B, Dalton RN, Dunger DB (2005) Longitudinal relation between limited joint mobility, height, insulin-like growth factor 1 levels, and risk of developing microalbuminuria: the Oxford Regional Prospective Study. Arch Dis Child 90:1039-1044

4. Rewers M, Pihoker C, Donaghue K, Hanas R, Swift P, Klingensmith GJ (2007) ISPAD Clinical Practice recommendations: assessment and monitoring of glycemic control in children and adolescents with diabetes. Pediatr Diabetes 8:408-418

5. Silverstein J, Klingensmith G, Copeland K (2005) Care of children and adolescents with type 1 diabetes. A statement of the American Diabetes Association. Diabetes Care 28:186-212

6. Hildebrandt P, Birch K, Sestoft L, Volund A (1984) Dosedependent subcutaneous absorption of porcine, bovine and human NPH insulins. Acta Med Scand 215:69-74

7. Acerini CL, Cheetham TD, Edge JA, Dunger DB (2000) Both insulin sensitivity and insulin clearance in children and young adults with type 1 (insulin-dependent) diabetes vary with growth hormone concentrations and with age. Diabetologia 43:61-68

8. Weissberg-Benshall J, Glasgow TM, Tynan WD, Wirtz P, Turck J, Ward J (1995) Adolescent diabetes management and mismanagement. Diabetes Care 18:77-83

9. Danne T, Mortensen HB, Hougaard P et al (2001) Persistent differences among centers in glycemic control and hyperglycemia in a study of 3,805 children and adolescents with type 1 diabetes from the Hvidore Study Group. Diabetes Care 24:1342-1347
10. Pickup J, Keen H (2002) Continuous subcutaneous insulin infusion at 25 years. Evidence base for the expanding use of insulin pump therapy in type 1 diabetes. Diabetes Care 25:593-598

11. Phillip M, Battelino T, Rodriguez H, Danne T, Kaufman F, for the Consensus Forum Participants (2007) Use of insulin pump therapy in the pediatric age-group. Diabetes Care 30:1653-1662

12. Tamborlane WV, Bonfig W, Boland E (2001) Recent advances in treatment of youth with type 1 diabetes: better care through technology. Diabet Med 18:864-870

13. Ahern JA, Boland EA, Doane R et al (2002) Insulin pump therapy in pediatrics: a therapeutic alternative to safely lower $\mathrm{HbAlc}$ levels across all age groups. Pediatr Diabetes 3:10-15

14. Danne T, Tamborlane WV (2006) Insulin pumps in pediatrics: we have the technology. We have the evidence. Why are still so few kids using it? Pediatr Diabetes 7(Suppl 4):2-3

15. Tamborlane WV (2006) Fulfilling the promise of insulin pump therapy in childhood diabetes. Pediatr Diabetes 7(Suppl 4):4-10

16. Danne T, Battelino T, Kordonouri O et al (2005) A cross-sectional international survey of continuous subcutaneous insulin infusion in 377 children and adolescents with type 1 diabetes mellitus from 10 countries. Pediatr Diabetes 6:193-198

17. Mortensen HB, Hougaard P (1997) Comparison of metabolic control in a cross-sectional study of 2,873 children and adolescents with IDDM from 18 countries. The Hvidore Study Group on Childhood Diabetes. Diabetes Care 20:714-720

18. Battelino T (2006) Risk and benefits of CSII treatment in school children and adolescents. Pediatr Diabetes 7(Suppl 4):20-24

19. Heidtmann B (2005) Insulinpumpentherapie bei Kindern und Jugendlichen. Therapieforum Diabetes 4:25-27

20. Danne T, von Schütz W, Lange K, Nestoris C, Datz N, Kordonouri O (2006) Current practice of insulin pump therapy in children and adolescents - the Hannover recipe. Pediatr Diabetes 7(Suppl 4):25-31

21. Pánkowska E, Skórka A, Szypowska A, Lipka M (2005) Memory of insulin pumps and their record as a source of information about insulin therapy in children and adolescents with type 1 diabetes. Diabetes Technol Ther 7:308-314

22. Burdick J, Chase HP, Slover RH et al (2004) Missed insulin meal boluses and elevated hemoglobin A1c levels in children receiving insulin pump therapy. Pediatrics 113:e221-e224

23. Holleman F, Gale EAM (2007) Nice insulins, pity about the evidence. Diabetologia 50:1783-1790

24. Mortensen HB, Robertson KJ, Aanstoot H-J (1998) Insulin management and metabolic control of type 1 diabetes mellitus in childhood and adolescence in 18 countries. Diabet Med 15:752-759

25. Kordonouri O, Hartmann R, Lauterborn R, Barnekow C, Hoeffe J, Deiss D (2006) Age-specific advantages of continuous subcutaneous insulin infusion as compared with multiple daily injections in pediatric patients: one-year follow-up comparison by matchedpair analysis. Diabetes Care 29:133-134

26. Fisher LK (2006) The selection of children and adolescents for treatment with continuous subcutaneous insulin in fusion (CSII). Pediatr Diabetes 7(Suppl 4):11-14

27. Weissberg-Benchell J, Antisdel-Lomaglio J, Seshadri R (2003) Insulin pump therapy. A meta-analysis. Diabetes Care 26:1079-1087

28. Plotnick LP, Clark LM, Brancati FL, Erlinger T (2003) Safety and effectiveness of insulin pump therapy in children and adolescents with type 1 diabetes. Diabetes Care 26:1142-1146

29. Dunger DB, Sperling MA, Acerini CL et al (2004) European Society for Paediatric Endocrinology/Lawson Wilkins Pediatric Endocrine Society Consensus statement on diabetic ketoacidosis in children and adolescents. Pediatrics 113:e133-e140

30. Hussein Z, Wentworth JM, Nankervis AJ, Proietto J, Colman PG (2004) Effectiveness and side effects of thiazolidinediones for type 2 diabetes: real-life experience from a tertiary hospital. Med J Aust 181:536-539 